\title{
EL PRINCIPIO DE PARETO EN EL CONTROL DOCUMENTAL DE PROGRAMAS INFORMATIVOS TELEVISIVOS: IMPLICACIONES EN EL MEDIA ASSET MANAGEMENT
}

\author{
THE PARETO PRINCIPLE IN THE \\ DOCUMENT CONTROL OF TELEVISION NEWS PROGRAMS: \\ IMPLICATIONS FOR MEDIA ASSET MANAGEMENT
}

Jorge Caldera Serrano ${ }^{1}$

\begin{abstract}
RESUMEN
Se analiza la reutilización de las colecciones audiovisuales de las cadenas de televisión con el fin de detectar si se cumple el Índice de Pareto, facilitando mecanismos para su control y explotación de la parte de la colección audiovisual menos utilizada. Se detecta que la correlación de Pareto se establece no sólo en el uso sino también en la presencia de elementos temáticos y elementos onomásticos en el archivo y en la difusión de contenidos, por lo que se plantea formas de control en la integración de información en la colección y de recursos en la difusión. Igualmente se describe el Índice de Pareto, los Media Asset Management y el cambio de paradigma al digital, elementos fundamentales para entender los problemas y las soluciones para la eliminación de problemas en la recuperación y en la conformación de la colección.
\end{abstract}

PALABRAS CLAVES: Procesamiento de la información. Televisión. Medios electrónicos. Evaluación del sistema de información.

\begin{abstract}
Reuse of audiovisual collections television networks in order to detect whether the Pareto index, providing mechanisms for control and exploitation of the least used part of the audiovisual collection holds analyzed. It is found that the correlation of Pareto is established not only in the use but also the presence of thematic elements and onomastic elements in the file and in the distribution of content, so forms of control arises in the integration of information collection and distributing resources. Likewise, the Pareto index, the Media Asset Management and the paradigm shift to digital, essential to understanding the problems and solutions to eliminate problems in recovery and in the establishment of collection elements described.
\end{abstract}

KEYWORDS: Information processing. Television. Electronic media. Information systems evaluation.

\section{INTRODUCCIÓN}

La gestión de la información en las organizaciones documentales dentro de los sistemas de información de las cadenas de televisión es sin lugar a dudas un tema que ha sido tratado por diferentes autores en la literatura científica en lengua castellana, tanto por autores que han sido traducidos (EDMONSON, 2004; DE JONG, 2003) y por autores españoles, tanto de la academia como de empresas audiovisuales (LÓPEZ DE QUINTANA, 2000; CALDERA-SERRANO; ARRANZ-ESCACHA, 2012; HIDALGO-GOYANES, 1999). No

\footnotetext{
1 Departamento de Información y Comunicación. Universidad de Extremadura. E-mail: jcalser@alcazaba.unex.es
}

Recebido em: 31/07/2015. Aceito em: 11/09/2015 
obstante, hemos de ser conscientes que la publicación de trabajos relacionados con esta disciplina dentro de las Ciencias de la Documentación es relativamente reciente, no contando con un importante número de autores. Es realmente a partir del cambio de paradigma, cambio al modelo digital, cuando ha existido una explosión en la producción de literatura científica en este ámbito, tratando los cambios producidos por el fenómeno digital a nivel general en diferentes niveles (AGUIRREAZALDEGUI-BERRIOZABAL, 2007; BUSTOS-PEREZ-DESALCEDO, 2007; GIMÉNEZ-RAYO, 2012; HIDALGO GOYANES, 2005, LÓPEZ DE QUINTANA, 2007) y también analizando elementos concretos (CALDERA Y SÁNCHEZ, 2008; PÉREZ; SANCHEZ Y CALDERA, 2008).

Por lo tanto, podemos llegar a señalar que sí existe una literatura consolidada en lengua castellana en dicho ámbito por medio de la publicación de autores españoles, no tanto es así por autores latinoamericanos que aún son poco proclives a la publicación, derivado en cierta manera del escaso número de autores que se dedican a esta materia.

Con la inmersión absoluta de los departamentos de documentación en el paradigma digital se han debido de reformular elementos relacionados con la selección, gestión documental e inclusión de metadatos, lectura de la imagen documental, difusión de contenidos, etc. Todo ha sido analizado para modificarlo a una nueva realidad donde la descripción documental ya no es un documento referencial que sirve para identificar el contenido, sino que el contenido está igual de disponible que los metadatos asociados. El cambio por tanto era absolutamente necesario.

Y entre dichos cambios, avalados por la mejora de las técnicas y métodos de almacenamiento masivo de imágenes, está el análisis de la conformación de la colección y de los problemas derivados de una menor descripción documental, además de una menor selección de contenidos audiovisuales.

En el presente trabajo se desea analizar cómo se conforman las colecciones para identificar no sólo la temática de dichos archivos audiovisuales sino el uso que sobre estos contenidos se hace. Para ello, y como método se estudia la implicación y adaptación del índice de Paleto en las colecciones audiovisuales y los problemas que genera en la recuperación documental en lo que se refiere al fenómeno de ruido.

El método empleado en el trabajo se ha basado en la revisión bibliográfica en primer lugar, para después por medio de la experiencia en centros españoles y latinoamericanos, reconocer los usos de la información y cómo han evolucionado los métodos de recuperación de contenidos en los Media Asset Management de las cadenas de televisión.

\section{ÍNDICE DE PARETO}

Tal y como señalan Valdiviezo Márquez y Simón Fermín (2010) la distribución de Pareto fue propuesta por Pareto en el año 1897 como un modelo para distribuciones de ingreso aunque actualmente es utilizada para describir otras muchas distribuciones. Centrado 
en estudios estadísticos es importante para el estudio sobre el tamaño poblacional, análisis de la riqueza global y local, poblaciones en ciudades, acontecimientos que involucren riquezas, riesgos y fallas comerciales, etc. Pickands (1975) cambió su denominación hacia "Distribución de Pareto Generalizada (GENERALIZED PARETO DISTRIBUTION, GPD)".

Aunque su valor se ha centrado en las ingenierías y disciplinas como la estadística, matemáticas, etc. en las Ciencias Sociales también ha sido utilizado el índice de Pareto, incluso ha sido la explicación para cuestiones muy locales e incluso del ámbito de la explicación de hábitos relacionados con el comportamiento humano.

De forma estandarizada el principio de Pareto es conocida como la regla del 80-20 derivado del estudio inicial que utilizó Pareto para llegar a la definición de su principio. Centrado en el estudio social analizó la relación entre los "pocos de mucho" y los "muchos de poco", de tal manera que el $80 \%$ de la población contaban con el $20 \%$ de algo, mientras que el $20 \%$ de la población tenían el $80 \%$ de algo. Pareto lo analizó para diferentes aspectos, y aunque él mismo señala que dicha distribución no es siempre exacta se mueve cerca de dichos parámetros.

Este principio ha sido utilizado con éxito en política y economía, en distribución de la riqueza, en estudios políticos, en estudios sociales, reparto de bienes naturales, en logística, en control de calidad, en ingeniería computacional, en el estudio de redes telemáticas, etc.

En el ámbito de las Ciencias de la Información se ha utilizado de forma tradicional para explicar el fenómeno de la utilización de los fondos bibliográficos de una biblioteca, aunque pueda ser extensible a otros tipos de colecciones. Según esta aplicación a la Biblioteconomía el $80 \%$ de la colección es utilizado en un $20 \%$ de las ocasiones, y por lo tanto, un $20 \%$ de la colección se utilizada en el $80 \%$ de las ocasiones. Este tipo de estudio nos lleva a plantearnos cuestiones como la conformación del fondo, selección de documentos a integrar en nuestra colecciones, políticas de expurgo, e incluso gustos y aficionas de los usuarios de una colección concreta, dando pautas sobre las modas informativos y tendencias. Evidentemente esta proporción de uso de la colección nos señala que los contenidos no están siendo utilizados de manera correcta por lo que deberíamos mejorar de forma significativa las políticas de selección, adquisición e incluso difusión de estos contenidos.

\section{GESTIÓN DE LA DOCUMENTACIÓN AUDIOVISUAL: LOS MEDIA ASSET MANAGEMENT}

En una encuesta realizado en el año 2015 por la empresa Ovum para Avid realizada entre 125 directivos de todo el mundo, dos terceras partes señalan que el uso de los Media Asset Management (MAM) han permitido la reducción de los costes de distribución, mientras que la mitad de ellos señalan la mejora en la colaboración y en el aumento de los ingresos (PANORAMA AUDIOVISUAL, 2015a). 
Dichos ingresos radican en que gracias a los MAM en lo referente a colaboración, costes de distribución han asyudado a encontrar nuevos nichos de negocio para la adquisición de recursos económicos para las empresas.

En Panorama Audiovisual (2015a) señalan sobre dicha encuesta que:

"Los datos recogidos muestran que los ejecutivos de los medios están percibiendo una evolución del MAM de un contenido multimedia independiente en un repositorio de almacenamiento a un facilitador de los flujos de trabajo de producción y distribución de activos de extremo a extremo de forma integrada. Mediante la implementación de un sistema MAM unificado, las empresas de media pueden agilizar la distribución de activos multiplataforma y monetizar activos de primera calidad canales lineales y no lineales", (palabras de Cedar Mohite, analista de Media \& Broadcast en Ovum).

Según Mario Díaz, representante de la empresa EVN, existe un claro incremento en el uso de los MAM por parte de las organizaciones, derivado de la evidencia de contar con sistemas sólidos y fiables para la gestión de contenidos por la creciente irrupción de las segundas pantallas, vídeo bajo demanda, la distribución de contenidos por plataformas de streaming y la mutación en los hábitos tradicionales de consumo de información audiovisual (PANORAMA AUDIOVISUAL, 2015b).

Aguirreazalgui (2007) cuenta con un trabajo que resume los MAM tanto a nivel general -en el sistema de televisión- como su ramificación en el servicio de documentación. Aunque los MAM aparecen entre el año 1999 y 2000, no será hasta el 2006 cuando comience a cobrar importancia. Un MAM es "un centro de gestión de los activos audiovisuales para su transmisión por redes diversas. Cumple las siguientes funciones: reutilización de contenidos, distribución, emisión, archivo y soporte a actividades de producción", siendo necesario la integración de diferentes tecnologías para la edición, archivo, búsqueda, transmisión, y todo ello en diferente formatos y en diferente resolución de señal.

Señala que el flujo informacional cuenta con los siguientes pasos: a) ingesta, integración de la señal de vídeo de las diferentes fuentes de información en el sistema, basado en la grabación de la señal en servidores tanto en alta resolución como en baja resolución b) almacenamiento, ubicar los contenidos ingestados en los servidores, asociando aquellos metadatos heredados de las fuentes externas y de la propia generación de los contenidos; c) catalogación, de los recursos captados por la empresa, asociando metadatos para que la información pueda ser posteriormente recuperada, aportando información onomástica, geográfica, cronológica, temática, así como datos de producción, de difusión, etc. (Caldera y Arranz, 2012); d) búsqueda, recuperación y edición, de las imágenes recuperadas en el sistema, siendo accesible tanto por los profesionales de la documentación como directamente por parte de los periodistas, que pueden organizar, montar, locutar, editar, la información desde su propio terminal; e) archivo, los componente de almacenamiento está conformado por el robot de cintas, la base de datos y el servidor de vídeo; y f) tráfico, módulo encargado del enrutamiento de la señal de vídeo por la red del sistema entre los requerimientos de imagen. 


\section{ÍNDICE DE PARETO Y EN LOS MAM}

Se quisiera en primer lugar acotar el estudio, ya que se va analizar el índice de Pareto y su forma de control atendiendo a la gestión de la información audiovisual en las organizaciones televisivas, siendo un elemento vertebrador y fundamental en los MAM, que deben entenderse dentro de la teoría de sistema en que todos los elementos están interconectados para que todo funcione de manera correcta. Por lo tanto, el módulo o sistema de gestión de la información audiovisual es un elemento nuclear dentro de un sistema mayor que son los MAM.

Y es en este entorno donde podemos apreciar como el principio de Pareto funciona en diferentes elementos que pueden modificar en cierta manera las políticas de los sistemas de información de las empresas televisivas.

Antes quisiéramos destacar algunos de los cambios más significativos desde la perspectiva documental que ha acarreado el cambio de paradigma, del obsoleto analógico al cambiante digital. Y señalamos cambiante ya que desde la inclusión real de los sistemas MAM en el año 2006 se han ido ajustando los métodos y formatos de trabajo, tanto es así que algunas empresas han encontrado grandes problemas para el cambio derivados tanto del problema tecnológico como de las necesidades de recursos humanos con capacidad para adaptarse a los nuevos métodos y hábitos.

En los servicios de documentación, especialmente en los comienzos de siglo XXI, existieron problemas para mutar las formas tradicionales de gestión a los nuevos métodos digitales, de tal forma que durante un tiempo se seguía analizando y trabajando con formatos digitales pero con una mentalidad absolutamente analógica, cuando los cambios que genera la incorporación de los MAM y el uso de la información audiovisual digital en el sistema documental hace que muchos de los antiguos métodos ya no tengan ningún sentido.

El primer elemento que se quiere destacar es que la labor de incorporación de descriptores de descripción y de recuperación del contenido no sólo son aportados por el personal del servicio de documentación. Desde la ingesta de la información audiovisual en el sistema, incluso antes en algunos casos, la información viene y está asociados a una serie de metadatos que pueden ir incorporando tanto el personal de la cadena como fuentes externas de información. Por lo tanto, cuando el contenido audiovisual llega al departamento de documentación para su análisis la primera labor será verificar los metadatos aportados por entes externos, incorporándolos a la descripción. Un tema relevante que queremos dejar aquí más para la reflexión que para el análisis es una realidad que está comenzando a practicarse en algunas cadenas: la adquisición de la gestión documental por parte de documentalistas externos a la propia cadena: esto ocurre con la gran cantidad de información asociada (metadatos) que tiene la información procedente de los despachos de agencia internacional, sobre todo, y también la obligatoriedad por acuerdos contractuales por medio de los cuales algunas empresas obligan normalmente a las productoras a enviar el producto terminado con los metadatos de descripción. En este segundo caso, los metadatos asociados serán marcados 
por la propia empresa televisiva, por lo que únicamente se deberá revisar el trabajo externo. Por el contrario, los metadatos procedentes de las agencias deberán ser asumidos tal y como llegan, o realizar nuevamente la labor de descripción, lo cual a la vista del mucho trabajo y los escasos recursos humanos es cada vez más difícil (CALDERA-SERRANO, 2015).

Otro factor relevante es que el documentalista en los nuevos MAM ha dejado de ser el puente entre la información y el periodista, el auténtico puente es el sistema, el MAM, los software de gestión documental que da acceso a los contenidos audiovisuales de la cadena. Es muy relevante derivado de los cambios en la gestión de la información. El periodista recupera directamente y sólo visitará el departamento de documentación en caso de no encontrar la información concreta que busca o querer ampliar. El usuario busca imágenes que tiene en su cabeza, que ha visto o que ha grabado, y rara vez profundiza en el material no emitido. De igual manera la terminología utilizada está absolutamente alejada del control terminológico por lo que parece oportuno adaptar la terminología de la descripción documental a la terminología usada por nuestros usuarios, en este caso los periodistas. Por lo tanto, en las plataformas digitales cada vez tiene una menor presencia el lenguaje controlado frente a mayores posibilidades de acceso en lenguaje libre.

Y como último elemento que se desea destacar, y asociado a los elementos anteriores, es que derivado del proceso de digitalización de las imágenes y su acceso a través de los MAM la gestión documental y específicamente la descripción de las imágenes en movimiento es mucho menos exhaustiva. El motivo radica en que con el material analógico no se contaba de manera rápida con las imágenes sino con una referencia, por lo que posteriormente se debía buscar el material en el depósito y las imágenes en las cintas. En los nuevos sistemas MAM junto a los metadatos recuperados, e incluso a la descripción de las imágenes, está la propia imagen en baja resolución. No sólo recuperar información referencial sino la propia imagen que está a un clic de distancia. Además los MAM facilitan keyframes representativos del contenidos por lo que en muchos casos no es ni tan siquiera necesario el acceder al contenido con el fin de analizar su validez o rechazo atendiendo a las necesidades informativas del momento.

La digitalización ha hecho posible mayor rapidez de acceso, mejora en la producción de la información y también un abaratamiento en los costos para el almacenamiento y preservación del material. Esto significa que los procesos de selección son cada vez más laxos, especialmente derivados no tanto de la tecnología como de la falta de personal, lo que provoca junto a lo destacado anteriormente como una menor descripción documental, recuperación en texto libre y la accesibilidad a los contenidos por parte de los periodistas -los cuáles carecen de conocimientos documentales-, que se produzca un problema de ruido documental, con mucha información redundante y sin validez, y con la precisión en la recuperación cada vez en menores índices (aunque con mayor exhaustividad). El ruido documental debe ser controlado para todo los tipos de colecciones documentales, pero en las colecciones audiovisuales televisivas se ha gestado unas circunstancia que lo posibilitan y que incluso lo potencian. 
Si nos centramos en los programas informativos (específicamente en los noticiarios) podremos observar que es un periodismo absolutamente declarativo, donde la preponderancia del texto frente a las imágenes es total, de tal manera que en muchos casos la imagen es puramente acompañamiento, facilitando la base informativa en el contenido textual. Tan claro es el asunto que los periodistas de informativos montan y preparan la información comenzando por el audio, ajustando los tiempo a lo requerido por la escaleta. Una vez preparado el audio es cuando se incorpora el vídeo, el captado por los cámaras atendiendo a la noticia, material de archivo y el asociado a las declaraciones facilitadas por personajes relevantes para la información.

Si observan los personajes que aportan información en televisión se podrá observar que se repiten de manera constante, siendo escaso el número de personajes anónimos que intervienen, y siempre en cierto tipo de noticias. Frente al periodismo declarativo existente, la temática principal es la información política, por lo que ahí sí que es absolutamente repetitiva, pudiendo afirmar que sí se cumple el Índice de Pareto en la aparición de personas que aparecen en la información: un $80 \%$ de apariciones esta copado por el $20 \%$ de las personas con las que contamos imágenes en el archivo. Por lo tanto, esto provocará una saturación de estos personajes en la colección audiovisual, generando gran problema de ruido a la hora de recuperar los contenidos por estos personajes.

La única manera de solucionar el problema de ruido en la recuperación es en la fase de confección de la colección por parte del proceso de selección. No parece oportuno el conservar siempre que aparezca ese personaje en pantalla, ya que volvemos a señalar que unos pocos son los que suelen aparecer muchas veces. Siendo conscientes de que los personajes llevan asociados unas declaraciones, que pasan como moda periodística muy rápidamente salvo casos muy contados, se analizará el material atendiendo a criterios periodísticos y documentales, la necesidad de preservar el recurso o un total de un personaje popular o reconocido. De tal manera que se indicará en un documento de preservación de personajes populares, cuándo y en que ambiente (interior o exterior) se ha conservado el personaje, para no tener que incorporar más veces de las necesarias dicho personaje a la colección (atendiendo exclusivamente a criterios de imágenes).

Hemos de tener presente que las colecciones audiovisuales de las televisiones no son diferentes a otros tipos documentales, y existen colecciones muy sobredimensionadas ya que el uso de los recursos suele ser repetitivo. Aquí también se cumple el Índice de Pareto, de tal manera que el $20 \%$ de la colección es utilizada en el $80 \%$, lo que se traduce que tenemos $4 / 5$ de la colección infrautilizada (y cierta parte, seguro, sin utilizar). Y sólo hablamos de información audiovisual ya digitalizada, los soportes analógicos son mucho menos utilizados, dejando realmente de ser en algunos casos colecciones en activos, sino almacenes sin uso.

Por lo tanto, debe realizarse un control de presencia en el archivo de los principales personajes visualizados en la información televisiva, pero no sólo debemos actuar en esa línea. Se deberá registrar el uso realizado del material audiovisual, implementando un metadato de fecha que señale sus diferentes reutilizaciones. De esta manera se controlará la 
reutilización de las imágenes para no utilizar siempre los mismos. Ese efecto, la reutilización constante de los mismos recursos, es negativa para la empresa desde el momento que el telespectador tiene una buena memoria visual y ver constantemente los mismos recursos provocará un rechazo a la información al ser reconocida nuevamente.

De orden muy similar ocurre con los temas que se visualizan y tratan los informativos. Aquí también se cumple el índice de Pareto y cierta manera es lógico, ya que las noticias no son un hecho aislado sino que tiene relación con sus antecedentes y tendrá que ver con los consecuentes. Para controlar esta reiteración de los contenidos no será necesario el control temático de las noticias sino el control de la reutilización de los fragmentos, o noticias completas, de material de archivo. Controlar la reutilización será igual de fácil que para el material onomástico, de tal manera que se asociará un valor en un campo del sistema de gestión documental dentro del MAM para que cada vez que se uso una información audiovisual para la emisión sea recordada.

Volvemos al siempre presente periodista. Y aquí nos encontramos como otro problema derivado de la nueva presencia de los porcentajes descritos por Pareto: si el periodista recupera información siempre recuperará la misma, ya sea por que la ha visto en la emisión, ya sea por ser captada por él de forma directa o por que haya usado con anterioridad. Recordamos que el periodista accede directamente a los contenidos sin pasar por el tamiz del gestor documental, por lo que tendremos un problema de reutilización de contenidos de forma constante sin un posible control profesional por parte del documentalista.

Se debe aportar información audiovisual relacionada a los requerimientos recuperados por el periodista, es decir, se les debe facilitar alternativas a las consultas realizadas facilitando recursos similares y que han sido utilizado un menor número de veces. Esto puede ser controlado de forma interna por el MAM, de tal manera que para el periodista sea una ponderación de resultados durante la presentación de contenidos recuperados. De esta manera facilitaremos al periodistas recursos relacionados que podía desconocer y ser igualmente válidos, e incluso mejorar sus expectativas en algunos casos; mientras que por otro lado se mejora el uso total de la colección y la no reutilización de forma constante de los mismos recursos.

Esta cuestión plantada para la información propia generada por la cadena es extrapolable igualmente para las imágenes que procede de las agencias de noticias (agencias de información), las cuáles contienen información de carácter internacional. Éstas son igualmente redundantes, repetitivas, especialmente en lo referente al contenido temático, no tanto a las imágenes las cuáles suelen ser por definición novedosas (aunque no sea siempre así). Por lo tanto, debemos controlar de la misma manera la información procedente de las agencias que la información generada por la propia empresa televisiva.

En resumen, el control de la colección por medio de las técnicas propuesta no deja de ser la manera de que el Índice de Pareto deje de ser una realidad en el uso de la información 
en las cadenas de televisión, con el fin de que la colección sea explotada en un mayor porcentaje aumentado de esta manera la calidad del producto audiovisual ofrecido.

\section{CONCLUSIONES}

Las colecciones audiovisuales no son muy distintas a la hora de la utilización de sus contenidos que otras colecciones documentales, incluso el Índice de Pareto viene acentuado desde el momento en que en la generación de la información que ingresa también lo padece. Esta realidad que puede ser interpretada como un problema es realmente una oportunidad, ya que hace previsible el ingreso e incluso los porcentajes de redundancia en la recuperación.

De ahí, que puedan llevarse a cabo mecanismos correctores tanto en la selección de la información que conforma la colección como a la hora de la selección de imágenes de recursos audiovisuales temáticos u onomásticos, de tal manera que facilitemos al periodistas alternativas a las imágenes recuperadas. El fin último no sólo es que no se implemente una colección sobredimensionada y no utilizada, que también, sino que a la hora de la reutilización se utilice más volumen de recursos de la colección por el simple de hecho de llevar a cabo control de la reutilización y control en el ingreso (especialmente el de reutilización podría ser confeccionado de manera automática).

Por lo tanto el Índice de Pareto adaptado a la implementación y uso de las colecciones audiovisuales no es una solución, sino que es el síntoma de problemas que si no son solucionados en su totalidad sí que pueden al menor tener una mejora en los porcentajes.

\section{RECONOCIMIENTOS}

Este trabajo ha sido financiado por el Gobierno de Extremadura (Consejería de Educación, Ciencia y Tecnología) y el Fondo Social Europeo dentro del plan de apoyo a las actuaciones de los Grupos de Investigación inscritos en el catálogo de la Junta de Extremadura. GR10019.

\section{REFERENCIAS BIBLIOGRÁFICAS}

AGIRREAZALDEGI-BERRIOZABAL, T. Claves y retos de la documentación digital en televisión . El Profesional de la Información, v. 16, n. 5, p. 433-442, 2007.

\section{BUSTOS-PÉREZ-DE-SALCEDCO, P. Sistemas integrados y gestión documental. La experiencia en Telecinco. El Profesional de la Información, v. 16, n. 5, p. 450-455, 2007.}

CALDERA-SERRANO, J. Externalización de la gestión documental audiovisual en las televisiones por medio de productoras audiovisuales y agencias de noticias.

TransInformaçao, v. 27, n. 2, p. 145-156, 2015. 
CALDERA-SERRANO, J.; ARRANZ-ESCACHA, P. Documentación audiovisual en televisión. Barcelona: Editorial UOC, 2012.

CALDERA-SERRANO, J.; SÁNCHEZ-JIMENEZ, R. Ontología para el control y recuperación de información onomástica en televisión. EI Profesional de la Información, v. 17, n. 1, p. 86-91, 2008.

CALDERA-SERRANO, J.; ZAPICO-ALONSO, F. (2004). La fórmula de comunicación de Lasswell como método para implementar bases de datos documentales en los medios audiovisuales. Investigación Bibliotecológica, v. 8, n. 37, p. 110-131, 2004.

DE JONG, Annemieke. Los metadatos en el entorno de la producción audiovisual. México: [s.n.], 2003.

EDMONSON, R. Filosofía y principios de los archivos audiovisuales. París: Unesco. 2004

LÓPEZ DE QUINTANA, E. Documentación en televisión. In: Manual de documentación informativa. Madrid: Cátedra, 2000, p. 83-181.

GIMÉNEZ-RAYO, M. La documentación audiovisual en televisión en el mundo 2.0: retos y oportunidades. Trípodos, n. 31, p. 79-97, 2012.

HIDALGO GOYANES, P. Documentación audiovisual. En: Introducción a la documentación informativa y periodística. Sevilla: MAD, 1999, p. $473-486$.

HIDALGO GOYANES, P. La documentación audiovisual de las televisiones. La problemática actual y el reto de la digitalización. Documentación de las Ciencias de la Información, v. 28, p. 159-171, 2005.

LÓPEZ DE QUINTANA, E. Transición y tendencias de la documentación en televisión: digitalización y nuevo mercado audiovisual. El Profesional de la Información, v. 16, n. 5, p. 397-408, 2007.

PANORAMA AUDIOVISUAL (2015a). Los directivos de la industria confían cada vez más en los beneficios del Media Asset Management para impulsar el crecimiento. Disponível em: http://www.panoramaaudiovisual.com/2015/07/24/los-directivos-de-la-industria-confiancada-vez-mas-en-los-beneficios-del-media-asset-management-para-impulsar-el-crecimiento/ Acesso em: 15 de septiembre de 2015.

PANORAMA AUDIOVISUAL (2015b). Mario Díaz: "gestionar assets de manera eficiente es ya imprescindible en cualquier industria”. Disponível em: http://www.panoramaaudiovisual.com/2015/07/10/mario-diaz-gestionar-assets-de- 
manera-eficiente-es-ya-imprescindible-en-cualquier-industria/ Acesso em: 15 de septiembre de 2015.

PÉREZ-AGUERA, JR; SÁN CHEZ-JIMENEZ, R.; CALDERA-SERRANO, J. Adaptación de tecnologías stream y xml a centros de documentación en televisión. Revista Española de Documentación Científica, v. 27, n. 4, p. 441-454, 2004.

PICKANDS, J. Statistical Inference Using Extreme Order Statistics. Annuals of Statistics, v. 3, p. 119-131. 1975

VALDIVIEZO MÁRQUEZ, MR; SIMÓN FERMIŃ, J. Estimación de índices de capacidad de procesos usando la distribución generalizada de Pareto. Ingeniería industrial, año 9, n. 2, p. 93-106, 2010.

Como citar este documento:

CALDERA-SERRANO, Jorge. El Principio de Pareto en el control documental de programas informativos televisivos: implicaciones en el Media Asset Management. Revista Digital de Biblioteconomia e Ciência da Informação, Campinas, SP, v. 13, n. 3, p. 480-490, set. 2015. ISSN 1678-765X. Disponível em: <http://periodicos.sbu.unicamp.br/ojs/index.php/rdbci/article/view/ 8639461>. Acesso em: 18 Set. 2015. 